\title{
ANALISIS SCIENTOMETRIC DAN BIBLIOMETRIC UNTUK PEMETAAN BIDANG KEILMUAN DI PROGRAM STUDI PENDIDIKAN TEKNIK INFORMATIKA DAN KOMPUTER UNJ
}

\author{
Fathiah $^{1}$, Widodo ${ }^{2}$, Bambang Prasetya $\mathrm{Adhi}^{3}$ \\ ${ }^{1}$ Mahasiswa Prodi Pend. Teknik Informatika dan Komputer, Teknik Elektro, FT - UNJ \\ ${ }^{2,3}$ Dosen Prodi Pend. Teknik Informatika dan Komputer, Teknik Elektro, FT - UNJ \\ ${ }^{1}$ fathiahtia97@ gmail.com, ${ }^{2}$ widodo@unj.ac.id, ${ }^{3}$ bambang_padhi@yahoo.com
}

\begin{abstract}
Abstrak
Dalam bidang keilmuan diperlukan sebuah pemetaan yang tepat dan jelas untuk setiap bidang. Pemetaan tersebut dapat dijadikan sebagai bahan acuan dalam mepertimbangkan pengambilan keputusan yang relevan dengan bidang keilmuan yang dimiliki. Tujuan dari penelitian ini untuk melihat kecenderungan bidang keilmuan dengan cara pemetaan analisis scientometric dan bibliometric di program studi Pendidikan Teknik Informatika dan Komputer UNJ. Proses pemetaan ini dimulai dengan pengumpulan data mata kuliah, bimbingan skripsi dan artikel/makalah dosen. Kemudian, data tersebut dianalisis dan divisualisasikan dengan software VOSViewer. Hasil analisis menunjukkan kecenderungan bidang Computer Science berdasarkan mata kuliah, Information Technology berdasarkan bimbingan skripsi, dan Pendidikan berdasarkan artikel/makalah dosen.
\end{abstract}

Kata kunci : Bibliometric, Bidang Keilmuan, Scientometric.

\section{Pendahuluan}

Pendidikan Teknik Informatika dan Komputer (PTIK) merupakan salah satu program studi yang ada di Universitas Negeri Jakarta. Program studi ini baru terbentuk pada tahun 2010, dengan memiliki 3 peminatan yaitu multimedia, teknik komputer dan jaringan, dan rekayasa perangkat lunak. Masing-masing peminatan tersebut memiliki jumlah mata kuliah wajib yang berbeda. Berdasarkan Buku Pedoman Akademik (BPA) tahun 2015, ada sebanyak 48 mata kuliah bidang keahlian di prodi PTIK. Dengan rincian 7 mata kuliah wajib peminatan multimedia, 7 mata kuliah wajib peminatan teknik komputer dan jaringan, 7 mata kuliah wajib peminatan rekayasa perangkat lunak, dan 27 mata kuliah wajib bidang studi.

Jumlah mata kuliah tersebut bisa dikatakan tidak sebanding dengan jumlah dosen yang tersedia. Karena, dosen yang ada di PTIK hanya berjumlah 14 orang. Sehingga, 1 dosen memungkinkan mengampu minimal 2 mata kuliah atau bahkan bisa lebih dari itu. Hal ini dikarenakan keterbatasannya jumlah dosen yang tersedia. Melihat kondisi tersebut, maka terjadi ketidaksesuaian penugasan untuk mengajar dan mengampu mata kuliah tertentu terhadap bidang keilmuan yang dimiliki.

Selain itu, hal yang terjadi adalah proses pembimbingan skripsi yang tidak relevan dengan bidang keilmuan yang dimiliki. Ketidaksesuaian dan relevan tersebut juga terjadi karena belum terlihat secara jelas nya keterkaitan antara bidang keilmuan yang ada di PTIK dengan bidang keilmuan ACM (Association for Computer Machinery). Sehingga, dalam pengambilan keputusan penugasan tidak relevan dengan bidang keilmuan yang dimiliki nya, sebab tidak mempunyai pemetaan yang jelas.

Oleh karena itu, untuk meminimalisir terjadinya ketidaksesuaian dengan bidang keilmuan yang dimiliki, maka diperlukan sebuah pemetaan dalam bidang keilmuan. Hal ini guna untuk membantu dalam pengambilan keputusan yang relevan dengan bidang keilmuan. Pemetaan tersebut dilakukan dengan menggunakan metode analisis scientometric dan bibliometric. Scientometric adalah kuantitatif studi disiplin tentang mengukur dan menganalisis sains, teknologi dan inovasi. Sedangkan bibliiometric adalah studi tentang penggunaan dokumen dan pola publikasi di mana menggunakan metode matematika dan statistik. Hasil dari analisis scientometric berupa gambaran kecenderungan dalam bidang keilmuan di PTIK.

\section{Dasar Teori}

\subsection{Scientometric}

Scientometrics adalah pendekatan sistematis untuk menganalisis masa lalu, sekarang, dan masa depan perkembangan ilmu pengetahuan. Istilah scientometrics ini diciptakan oleh matematikawan Rusia bernama Vasiliy Nalimov. Scientometric memiliki beberapa tujuan, yaitu: 1. Mengukur, mengklasifikasikan, dan menggambarkan keluaran 
literatur ilmiah 2. Memahami penyebaran pengetahuan 3. Mengidentifikasi dampak teoretis dan praktis dari studi akademik 4. Memahami perilaku masing-masing peneliti, tim peneliti, dan lembaga 5. Mengeksplorasi sifat outlet ilmiah 6 . Menentukan alokasi sumber daya yang paling efisien untuk memaksimalkan hasil penelitian dan dampak 7. Mengusulkan rekomendasi untuk pengembangan kebijakan penelitian

\subsection{Bibiometric}

Bibliometric berasal dari kata biblio dan metrics, biblio berarti buku dan metrics berarti mengukur. Jadi, bibliometrika dapat diartikan sebagai kegiatan mengukur atau menganalisis buku atau literatur dengan menggunakan pendekatan matematika dan statistika (Diodato dalam Hartinah,2008:2). Sedangkan, menurut Esshra (2007:7) pengertian bibliometrics adalah sebuah studi atau ukuran dari aspekaspek yang formal pada teks, dokumen, buku dan informasi.

\subsection{Pemetaan Bidang Keilmuan}

Menurut kamus besar bahasa Indonesia pemetaan adalah proses, cara, perbuatan membuat peta. Peta ilmu menggambarkan hubungan ruang antara batas penelitian dalam bidang kegiatan yang signifikan, juga di mana bidang bidang penelitian itu didistribusikan serta dapat memberikan makna dari hubungan tersebut (Chen, 2003:33). Peta ilmu pengetahuan tidak hanya merupakan alat yang praktis untuk menyampaikan informasi mengenai aktivitas ilmiah, tetapi juga sebagai dasar untuk mengkaji atau memahami aktivitas ilmiah dengan menggambarkannya secara tersusun dan terstruktur. Visualisasi ilmu pengetahuan dapat diwujudkan dalam bentuk peta, sehingga muncullah bidang pemetaan pengetahuan atau (knowledge mapping). Pemetaan ilmu pengetahuan dapat dilakukan berdasarkan beberapa cara yang terkait erat dengan subjek dokumen.

\subsection{ACM}

Association for Computing Machinery (umumnya disebut ACM) adalah organisasi ilmiah dan profesional yang didirikan pada tahun 1947. Berkaitan dengan pengembangan dan berbagi pengetahuan baru tentang semua aspek komputasi (kata mesin dalam namanya adalah artefak sejarah). Secara tradisional rumah profesional para ilmuwan komputer yang merancang caracara baru menggunakan komputer dan yang memajukan ilmu pengetahuan dan teori yang mendasari perhitungan itu sendiri dan perangkat lunak yang memungkinkannya.

\section{Metodologi}

\subsection{Tempat dan Waktu Penelitian}

Penelitian ini dilakukan di Laboratorium Komputer Gedung L1 Teknik Elektro lantai 2, Fakultas Teknik, Universitas Negeri Jakarta yang berlokasi di Jalan. Rawamangun Muka, Jakarta Februari hingga Juli 2019. Literature review terhindar dari bias dan pemahaman.

\subsection{Metode Penelitian}

Metode yang digunakan dalam penelitian ini adalah dengan menggunakan metode analysis scientometric dan bibliometric. Peneliti akan melakukan analisis dengan menggunakan beberapa metode pada analysis scientometric dan bibliometric berdasarkan data yang diperoleh, kemudian akan menghasilkan sebuah pemetaan yang akan divisualisasikan dengan software VOSviewer.

\subsection{Data dan Sumber Data}

Data yang digunakan berupa hasil wawancara dengan dosen di prodi Pendidikan Teknik Informatika dan Komputer dan hasil pencarian sumber data scientometric melalui mesin pencarian, google scholar, sinta ristekdikti, scopus, dan researchgate. Pencarian hasil data tersebut yang akan digunakan penulis dalam melakukan penelitian ini.

\subsection{Teknik dan Prosedur Pengumpulan Data}

Pengumpulan data yang digunakan pada penelitian ini dengan menggunakan data dari mesin pencarian Google Scholar, Sinta Ristekdikti, Scopus, ResearchGate, dan Closer. Selain itu, peneliti juga melakukan wawancara dengan dosen di Prodi Pendidikan Teknik Informatika dan Komputer. Pengumpulan data yang diperlukan pada penelitian ini yaitu berupa jadwal mengajar seluruh dosen di Prodi Pendidikan Teknik Informatika dan Komputer, judul bimbingan skripsi yang dibimbing oleh dosen dan penelitian yang dibuat oleh dosen. Pada proses pencarian data publikasi hasil penelitian yang dibuat dan publikasi oleh dosen melalui mesin pencari, ada beberapa hal yang diperhatikan, seperti tingkat afilasi dan tingkat sitasi dari dokumen yang telah dibuat dan publikasi.

\subsection{Prosedur Analisis Data}

Untuk menganalisa data yang telah terkumpul dari hasil pencarian data dan wawancara, data tersebut akan diolah dengan menggunakan beberapa metode dari analysis scientometric dan bibliometric. Pada analysis scientometric menggunakan metode citation analysis, co-citation analysis, content analysis, dan co-author analysis. Sedangkan pada analysis bibliometric, menggunakan hukum lotka. 


\subsection{Pemeriksaan Keabsahan Data}

Pemeriksaan keabsahan data dilakukan wawancara secara langsung dengan dosen terkait dengan hasil penelitian yang pernah dibuat dan melakukan diskusi dengan dosen pembimbing terkait hasil penelitian.

\section{Hasil dan Analisis}

\subsection{Tahap Persiapan}

Tahap persiapan merupakan tahap awal dalam melakukan analisis scientometric dan bibliometric. Pada tahap ini penulis melakukan studi literature terkait analisis scientometric dan bibliometric, dan pencarian sumber data scientometric atau artikel/makalah dosen melalui google scholar, sintaristekdikti, dan scopus, mencari data jadwal mengajar dosen Program Studi Pendidikan Teknik Informatika dan Komputer UNJ, dan data bimbingan skripsi mahasiswa Program Studi Pendidikan Teknik Informatika dan Komputer UNJ.

\subsubsection{Mata Kuliah}

Tabel 4. 1 Mata Kuliah

\begin{tabular}{|c|c|c|c|}
\hline NO & MATA KULIAH & NAMA DOSEN & SEMESTER \\
\hline \multirow{3}{*}{1} & \multirow{3}{*}{ Jaringan Komputer } & Lipur & 95,97 \\
\hline & & Ficky D & $\begin{array}{l}99,101,103,105,107, \\
109\end{array}$ \\
\hline & & Bachren & $101,103,105,107,109$ \\
\hline \multirow{3}{*}{2} & \multirow{3}{*}{ Data Warehouse } & Widodo & 100 \\
\hline & & Bambang $\mathrm{P}$ & $102,104,106,108$ \\
\hline & & Ferdi Fauzian & $104,106,108$ \\
\hline \multirow{3}{*}{3} & \multirow{3}{*}{ Sistem Multimedia } & Hamidillah Adjie & $\begin{array}{l}94,96,98,100,102, \\
104,106\end{array}$ \\
\hline & & Fandy S & $104,106,108$ \\
\hline & & Prasetyo & 108 \\
\hline
\end{tabular}

Berdasarkan data jadwal mengajar dosen yang diperoleh pada table 4.1, terdapat sebanyak 90 mata kuliah, baik mata kuliah wajib, mata kuliah umum, pendidikan, maupun peminatan, yang terhitung mulai dari semester 093 sampai 109. Data jadwal mengajar semester 092 dan 110 tidak termasuk dalam pengumpulan data, karena UPT TIK masih dalam proses memperbaiki siakad yang belum sempurna. Untuk melihat mata kuliah lebih detail, ada dibagian lampiran. Setelah data jadwal mata kuliah program studi Pendidikan Teknik Informatika dan Komputer diperoleh, selanjutya data tersebut dilakukan pengkategorian didasarkan pada bidang ACM dan Kependidikan

\subsubsection{Bimbingan Skripsi}

Tabel 4.1.2. Kecenderungan Skripsi

\begin{tabular}{|l|c|}
\hline \multicolumn{1}{|c|}{ Bidang Ilmu } & Jumlah Skripsi \\
\hline Software Engineering & 88 \\
\hline Computer Science & 48 \\
\hline Information Software & 65 \\
\hline Computer Engineering & 1 \\
\hline
\end{tabular}

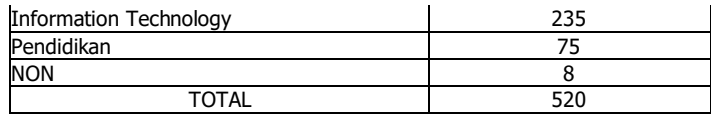

Berdasarkan tabel 4.1.2. di atas maka diperoleh tema skripsi yang dominan adalah pada bidang Information Technology.

\subsubsection{Artikel/Makalah Dosen}

Dalam melakukan pengumpulan data scientometric artikel/makalah dosen, penulis menggunakan dua mesin pencari, yaitu google scholar dan scopus.

\subsection{Tahap Pelaksanaan}

Pada tahap pelaksanaan ini penulis melakukan dua metode analisis, yaitu dengan cara analisis scientometric dan bibliometric, dengan hasil sebagai berikut:

\subsubsection{Analisis Scientometric}

Tabel 4.2.1 Hasil Analisis Scientometric

\begin{tabular}{|c|c|c|c|c|c|c|c|c|c|c|c|}
\hline \multirow{2}{*}{ No } & \multirow{2}{*}{$\begin{array}{l}\text { Nama } \\
\text { Dosen }\end{array}$} & \multicolumn{6}{|c|}{ Kategori Artikel/makalah } & \multirow{2}{*}{ Final } & \multirow{2}{*}{$\begin{array}{c}\text { Total } \\
\text { Artikel/ma } \\
\text { kalah } \\
\end{array}$} & \multirow{2}{*}{$\begin{array}{c}\text { Co- } \\
\text { Author }\end{array}$} & \multirow{2}{*}{ Autho } \\
\hline & & $\mathrm{CE}$ & $\mathrm{CS}$ & IS & $\mathrm{SE}$ & IT & $\mathrm{P}$ & & & & \\
\hline 1 & ivan & & & & & 1 & 16 & $\mathrm{P}$ & 17 & 21 & 23 \\
\hline 2 & fandy & & & & & & & & & 2 & 3 \\
\hline 3 & lipur & & 7 & & & 6 & 6 & CS & 19 & 10 & 11 \\
\hline 4 & bambang & & 3 & 1 & & 2 & 1 & $\mathrm{CS}$ & 7 & 9 & 10 \\
\hline 5 & diat & & & 2 & & 2 & 1 & IS/IT & 5 & 8 & 9 \\
\hline 6 & prasetyo & & & 2 & & 2 & 1 & IS/IT & 5 & 4 & 4 \\
\hline 7 & hamidillah & & 2 & 1 & & 1 & & $\mathrm{CS}$ & 4 & 5 & 5 \\
\hline 8 & erda & & & & & & 3 & $\mathrm{P}$ & 3 & & 1 \\
\hline 9 & bachren & & & & & 1 & 1 & $\mathrm{IT} / \mathrm{P}$ & 2 & 2 & 3 \\
\hline 10 & ficky & & & & & 2 & 1 & IT & 3 & 4 & 4 \\
\hline 11 & widodo & & 10 & & 5 & 1 & & CS & 16 & 11 & 4 \\
\hline 12 & ferdi & & & & & & 1 & $\mathrm{P}$ & 1 & 2 & 2 \\
\hline 13 & vina & & 1 & & & 3 & & IT & 4 & 5 & 5 \\
\hline 14 & yuliatri & & & & & & 5 & $\mathrm{P}$ & 5 & 9 & 8 \\
\hline & TOTAL & & 23 & 6 & 5 & 21 & 36 & 0 & 91 & 92 & 92 \\
\hline
\end{tabular}

Jumlah rata-rata artikel/makalah/penulis per bidang ilmu:

1. $\mathrm{CE}=0$

2. $\mathrm{CS}=\frac{7+3+2+10+1}{5}=\frac{23}{5}=4,6$

3. IS $=\frac{1+2+2+1}{4}=\frac{6}{4}=1,5$

4. $\mathrm{SE}=\frac{5}{1}=5$

5. IT $=\frac{1+6+2+2+2+1+1+2+1+3}{10}=\frac{21}{10}=2,1$

6. $P=\frac{16+6+1+1+1+3+1+1+1+5}{10}=\frac{36}{10}=3,6$

Total rata-rata artikel/makalah/penulis:

$\frac{17+8+7+5+5+4+3+2+3+16+1+4+5}{13}=\frac{90}{13}=6,92$

Berdasarkan perhitungan diatas, maka jumlah ratarata artikel/makalah yang ditulis oleh setiap dosen dalam masing-masing kategori bidang ACM yaitu:

1. CE sebanyak 0 
2. CS sebanyak 5 artikel/makalah

3. IS sebanyak 2 artikel/makalah

4. SE sebanyak 2 artikel/makalah

5. IT sebanyak 2 artikel/makalah

6. Pendidikan sebanyak 4 artikel/makalah

Kemudian, jumlah rata-rata setiap dosen dalam menulis artikel/makalah dalam keseluruhan bidang ilmu itu sebanyak 7 artikel/makalah, dan penulisan artikel/makalah terbanyak ada pada kategori Computer Science.

\subsubsection{Analaisis Bibliometric}

Analisis sitasi adalah hitungan kutipan sebenarnya menunjukkan berapa kali suatu artikel dikutip oleh dokumen lain. Pengindeksan saat ini sistem mendapatkan jumlah kutipan dari bagian referensi mengutip dokumen.

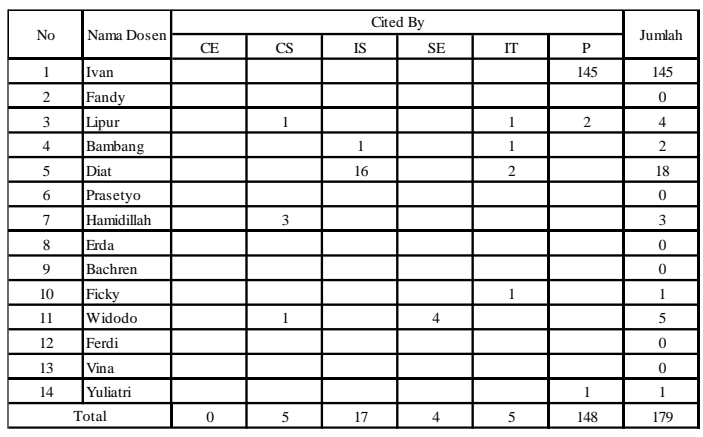

Gambar 4.2.2. tabel analisis bibliometric

\subsection{Visualisasi VOSViewer}

Dari hasil data scientometric melalui mesin pencarian google scholar, sinnta ristekdikti dan scopus kemudian dokumen di-export ke format CSV, di-input dan dianalisis dengan VOSViewer diperoleh hasil sebagai berikut

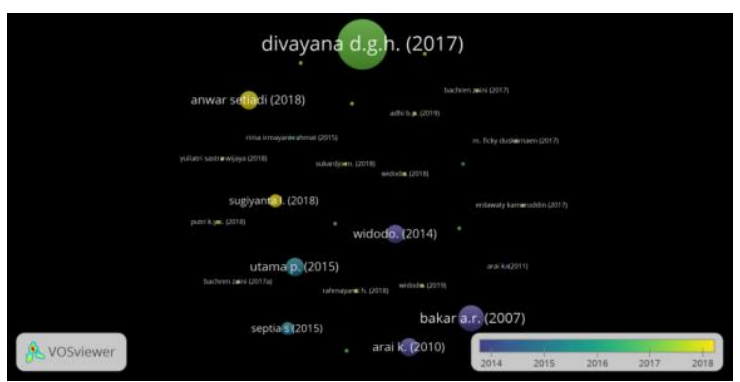

Gambar 4.3 Visualisasi overlay Peta Citation Document

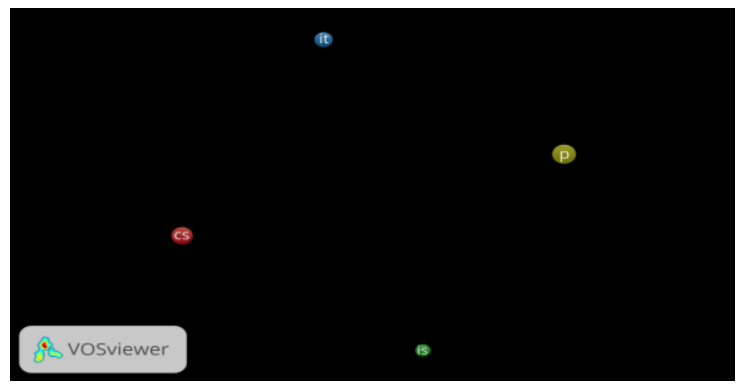

Gambar 4.3.1. Visualisasi network Peta Bidang ACM

\subsection{Pembahasan}

Berdasarkan data scientometric yang telah didapatkan dan dianalisis dengan analisis scientometric dan bibliometric, maka diperoleh data sebagai berikut. Bidang kecenderungan dosen Program Studi Pendidikan Teknik Informatika dan Komputer per bidang keilmuan berdasarkan jadwal mengajar mata kuliah yaitu dominan pada bidang Computer Science sebanyak 10 dosen, kemudian bidang Computer Engineering sebanyak 3 dosen, dan terakhir bidang Pendidikan sebanyak 2 dosen.

Selanjutnya, berdasarkan mesin pencari melalui google scholar dan scopus, jumlah artikel/makalah yang terkumpul sebanyak 91 artikel/makalah, namun dikarenakan adanya kesamaan nama dan judul artikel/makalah sebanyak 5 artikel/makalah, jadi hasil akhir jumlah artikel/makalah adalah 86 . Bidang keilmuan yang paling dominan berdasarkan artikel/makalah yaitu Pendidikan, berjumlah 36 artikel/makalah, yang memiliki beberapa judul artikel/makalah diantaranya Assessing employability skills of technical-vocational students in Malaysia, Pedoman Beban Kerja Dosen dan Evaluasi Pelaksanaan Tridharma Perguruan Tinggi, Vocational Curriculum Implementation of the Three Years Program of Electronics Engineering, dan Development of Teaching Materials Introduction to Statistics Using E-learning for Students of Jakarta State University. Setelah bidang Pendidikan, ada pada bidang Information Technology dengan jumlah artikel/makalah 20, yang memiliki beberapa judul artikel/makalah diantaranya Analisis, Perancangan, Dan Implementasi Jaringan Wireless Point To Point Antara Kampus A Dan Kampus B Universitas Negeri Jakarta, Pengembangan Media Pembelajaran Interaktif Contextual Teaching and Learning (CTL) Untuk Siswa Pendidikan Anak Usia Dini (PAUD) di PAUD SAHABAT, Analisis, Perancangan, dan Performance comparison of reporting engine birt, jasper report, and crystal report on the process business intelligence.

Bidang ilmu selanjutnya yaitu Computer Science dengan jumlah artikel/makalah 19, yang memiliki beberapa judul artikel/makalah diantaranya A framework of human emotion recognition using extreme learning machine, Java character 
recognition using Hopfield network, Rule Based Scoring For User And Non-playable Charachter (NPC) Base On Fuzzy Logic, dan Energy Behavior in Ad Hoc Network Minimizing the Number of Hops and Maintaining Connectivity of Mobile Terminals Which Move from One to the Others. Kemudian, bidang ilmu Information Software dengan jumlah artikel/makalah 6, yang memiliki beberapa judul diantaranya Sistem Pendukung Keputusan Untuk Menentukan Penerima Beasiswa Di Fakultas Teknik Univeristas Negeri Jakarta Dengan Model Fuzzy Multiple Attribute Menggunakan Metode Saw, Perancangan Dan Pengembangan Aplikasi Sistem Informasi Monitoring Perkuliahan Dan Kehadiran Mahasiswa Berbasis Web, dan Development of Webbased Information System for Universitas Negeri Jakarta. Lalu ada bidang Software Engineering dengan jumlah artikel/makalah 5, yang memiliki beberapa judul artikel/makalah seperti Requirements Management Pada Extreme Programming, Extreme Programming: Pengembangan Perangkat Lunak Semi Formal, dan Agile Methods: The Requirement Engineering Method to Support eXtreme Programming. Terakhir, ada pada bidang keilmuan Computer Engineering dengan jumlah artikel/makalah sebanyak 0 artikel/makalah.

Terakhir, berdasarkan data bimbingan skripsi, maka memiliki dominan pada bidang Information Technology dengan jumlah skripsi sebanyak 235, kemudian Software Engineering sebanyak 88, bidang Pendidikan sebanyak 75, lalu Information System berjumlah 65, Computer Science berjumlah 48, Non ACM dan Pendidikan 8, dan terakhir Computer Engineering sebanyak 1

\section{Kesimpulan dan Saran}

\subsection{Kesimpulan}

Kesimpulan mengenai bidang keilmuan yang ada di Program Studi Pendidikan Informatika dan Komputer melalui analisis scientometric dan bibliometric, maka diperoleh hasil sebagai berikut:

1. Berdasarkan data dosen terhadap mata kuliah yang disesuaikan dengan bidang keilmuan ACM (Association for Computing Machinery), maka cenderung terhadap bidang Computer Science, dengan jumlah dosen sebanyak 10 orang, kemudian bidang Computer Engineering sebanyak 3 dosen, dan terakhir bidang Pendidikan sebanyak 2 dosen.

2. Berdasarkan data dosen terhadap bimbingan skripsi, maka cenderung terhadap bidang Information Technology dengan jumlah skripsi sebanyak 235, kemudian Software Engineering sebanyak 88, bidang Pendidikan sebanyak 75, lalu Information System berjumlah 65 , Computer Science berjumlah 48, Non ACM dan Pendidikan 8, dan terakhir Computer
Engineering sebanyak 1.

3. Berdasarkan data dosen terhadap artikel/makalah yang dihasilkan, maka cenderung terhadap bidang Pendidikan dengan jumlah artikel/makalah sebanyak 36 artikel/makalah, lalu bidang Information Technology sebanyak 20 artikel/makalah, bidang Computer Science dengan jumlah artikel/makalah 19, kemudian ada pada bidang Information System sebanyak 6 artikel/makalah, bidang Software Engineering 5 artikel/makalah, dan terakhir bidang Computer Engineering sebanyak 0 artikel/makalah

\subsection{Saran}

Untuk penulisan penelitian dengan tema pemetaan bidang keilmuaan di Program Studi Pendidikan Teknik Informatika dan Komputer selanjutnya, penulis memiliki saran sebagai berikut

1. Melakukan wawancara kepada dosen untuk mengetahui lebih rinci terkait data yang diperlukan pada artikel/makalah dosen terkait

2. Analisis bibliometric untuk memetakan tingkat keusangan dokumen

\section{Daftar Pustaka:}

[FT] Fakultas Teknik. 2015. Pedoman Penulisan Skripsi. Jakarta: Fakultas Teknik, Universitas Negeri Jakarta.

Canavero, Flavio., dkk. 2014. Impact of Journals and Academic Reputations of Authors: A Structured Bibliometric Survey of the IEEE Publication Galaxy, 57: 1.

Hafni, Wildatul. 2018. Pemetaan Subjek Penelitian Pada Jurnal Bidang Ilmu Perpustakaan Dan Sains Informasi Terindeks Scopus Dan Web Of Science [skripsi]. Medan: Fakultas Ilmu Budaya.

Heilig, Leonard \& Vo $\beta$, Stefan. (2014). A Scientometric Analysis of Cloud Computing Literature, vol XX, no XX.

Natakusumah, Engkos Koswara. 2014. Penentuan Kolaborasi Penelitian Dan Distribusi Pengarang Pada Jurnal Teknologi Indonesia (The Determinations of Research Collaboration And Authors Distribution In The Jurnal Teknologi Indonesia), Bandung: Profesor Riset Pusat Penelitian InformatikaLIPI.

Ristiyono, M.P. 2008. Pemetaan Bidang Ilmu Berdasarkan Artikel Jurnal Pendidikan Universitas Terbuka Tahun 1999 - 2007: Menggunakan Analisis Co-Words [Tesis]. Bogor: Program Studi Magister Teknologi Informasi untuk Perpustakaan. 
Ravikumar, S., Agrahari, Ashutosh., Singh, S. N,. 2014. Mapping the intellectual structure of scientometrics: a co-word analysis of the journal Scientometrics (2005-2010). Hungary: Springer.

Serenko, Alexander. 2013. Meta-analysis of scientometric research of knowledge management: discovering the identity of the discipline. Canada: Faculty of Business Administration. 